\title{
Recycling of Pattern Wax In The Investment Casting Process Using Microwave Dewaxing
}

\author{
Doli Rani ${ }^{1}$, D.B. Karunakar ${ }^{2}$ \\ 1 Water Resources Development \& Management Dept., Indian Institute of Technology Roorkee, \\ Roorkee - 247 667, India \\ 2 Mechanical \& Industrial Engineering Dept., Indian Institute of Technology Roorkee, Roorkee - 247 667, India.
}

\begin{abstract}
For dewaxing in the investment casting process the use of microwave is steadily growing in industrial processes. The present work studies the possible influence of dewaxing on the wax properties in investment casting process using microwave oven. The wax blend made up of paraffin wax, microcrystalline wax, carnauba wax used in this work was prepared by melting in an oven equipped with a mineral oil bath. The chemical and structural stability of the wax were monitored throughout 10 dewaxing cycles, via various analyses, namely, linear shrinkage, volumetric shrinkage, hardness and roughness. The results showed that microwave dewaxing is viable, significantly decreasing the incorporation of dirt and water. The percentage of linear shrinkage and volumetric shrinkage is increasing gradually in each repeated cycle. The gradual change in linear shrinkage is less as compared to gradual change in volumetric shrinkage. The change in hardness is not following any pattern as it some times decreasing and some time increasing.
\end{abstract}

Key Words: Investment casting, wax blend, microwave oven, dewaxing, pattern properties.

\section{INTRODUCTION}

Investment casting (also known as 'lost wax casting' or 'precision casting') has been the most widely used process for several centuries. In this casting technique, a pattern, usually made of wax, is utilized to make the inside cavity of a refractory mould. The pattern is formed by injecting the molten wax into a permanent mould of the desired shape and there by cooling it until solidification. The pattern or a cluster of such patterns are gated together to a wax sprue. Then the sprued pattern is invested with ceramic slurry which is then solidified, forming a mould around the wax pattern. The wax pattern is then removed from the mould by melting or burning. The key steps involved in investment casting process are depicted in Fig 1.

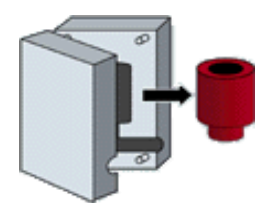

(a)

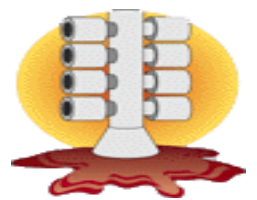

(d)

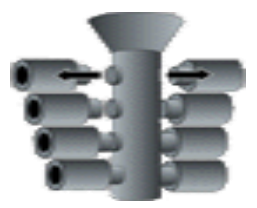

(g)

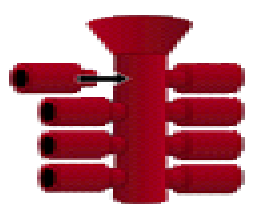

(b)

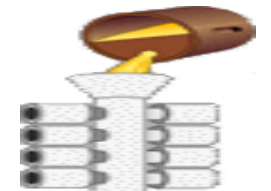

(e)

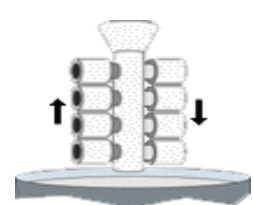

(c)

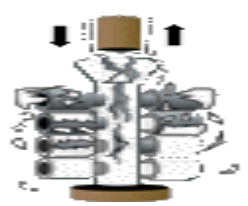

(f)

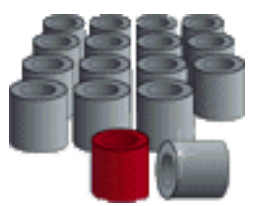

(h)

Fig 1 Basic steps involved in ceramic shell investment casting (a) Pattern production (b) Pattern assembly (c) Investment (d) Dewaxing (e) Casting (f) Knock-out (g) Cutoff (h) Finishing and inspection. 
Tascyogylu et al [1] found that waxes are the complex mixtures of many compounds including natural or synthetic wax, solid fillers and even water. Sabau and Viswanathan [2] investigated the effect of addition of the additives to the wax. Additives used for making pattern waxes included a variety of materials such as resins, plastics, fillers, oils and plasticizers. They concluded that dimensional changes between the pattern tooling and its corresponding cast part occur as a result of thermal expansion, shrinkage, hot deformation, and creep of the pattern material (wax), mould material (shell), and solidifying alloy during the processing.

Okhuysen et al [3] found that shrinkage of the wax is largest components of the overall dimensional changes between the pattern and its corresponding cast part. He used the computer model to predict the wax dimensions and concluded that, one of the main difficulties in using computer models for the prediction of wax dimensions is the lack of constitutive equations and material properties of the wax. He reported the results of a survey of 18 investment casting companies to determine the tooling allowance practices. It appears that there is no consistency in the way investment casters decide on the application of their tooling shrinkage allowances.

Gebelin and Jolly [4] explained that the accuracy of the wax patterns used has a direct bearing on the accuracy achievable in the final cast part. They also concluded that, it is useful for the investment caster to use precision-machined full -metal dies for producing wax patterns when large numbers of highly accurate components are required. Bonilla et al [5] found that the injection parameters play an important role in the accuracy of the wax patterns. These parameters include: the injection flow-rate; the injection cycle time; the injection temperature; the injection pressure; and the die temperature. Singh et al [6] also carried out similar investigations.

Liu et al [7] explained a new investment casting technology, 'freeze cast process' with ice as the pattern material. The advantage of ice pattern is that it prevents shell cracking during pattern removal. Liu et al [8] found that most production wax patterns exhibit an abrupt expansion as the crystalline portion of the microstructure melts during de-waxing. In contrast, the ice pattern will shrink, thus relieving the stress on the shell during pattern removal. The cracking of the shell can be eliminated by making ice patterns with the rapid freeze prototyping (RFP) process.

Rezavand and Behravesh [9] made an experimental study on dimensional stability of simplified wax models. The focus of their experimental work was on the injection stage, investigating the effects of processing parameters and the shrinkage of critical dimensions. They had chosen injection temperature and holding time as variable processing parameters and concluded that, the final dimensions of wax pattern are affected by: (i) type of wax; (ii) geometry of part and (iii) process parameters.

Horacek and Lubos [10] studied the influence of injection parameters on the dimensional stability of wax patterns and found that there exists an interrelationship between injection parameters like injection temperature, die temperature, injection force, holding time and their dependency on dimensional parameters. Yarlagadda and Hock [11] determined the accuracy of wax patterns produced by hard (polyurethane mould) and soft (RTV mould) tooling and optimized the injection parameters used in a low-pressure injection moulding. Tascroglu and Akar [12] carried out investigations on different additives used in making wax patterns and found that the addition of soybean flours of different varieties to the pattern wax material could improve surface roughness, shrinkage, hardness and tensile strength.

From the above review, it is clear that a considerable work has been carried-out on the pattern materials of investment casting. The ice pattern gives the better dimensional accuracy and there are less chances of cracking of shell, but the investigation of surface finish of ice pattern is very difficult. Frozen mercury can be used as a pattern material as it does not expand in changing from the solid (frozen) to the liquid state. However, a major disadvantage of mercury pattern is the requirement for keeping it at extremely low temperature and the other disadvantage is its high cost. Ultimately, wax (or wax blend) seems to be the better pattern material which is available at a lower cost, yet can produce balanced properties. The quality of an investment casting can be increased by improving one or more characteristics of the pattern wax, mentioned above, without spoiling the others, through blending. However, from the above review, it is evident that no systematic approach was carried out to design the wax blends. Hence, in the present study, an attempt is made to design a wax blend that would offer optimum properties. An attempt is also made to investigate the variation in the properties of wax blend when the dewaxing is carried out using a microwave oven.

Different phases of work carried out in this work are mentioned below.

a) Selection of different wax blends for pattern making.

b) Experimental determination of the wax blends behaviour under different process reduces extra space parameters.

c) Experimental determination of shrinkage (linear/volumetric), surface roughness and hardness of wax blend patterns produced.

d) Selection of best wax blend.

e) Dewaxing of wax model in microwave oven.

f) Evaluation of properties of wax in each repeated cycle. 


\section{A. Paraffin wax}

\section{SELECTION OF WAX BLEND}

Paraffin is a class of aliphatic hydrocarbons characterized by straight or branched carbon chains, generic formula $\mathrm{CnH} 2 \mathrm{n}+2$. Their physical properties vary with increasing molecular weight from gases to waxy solids. Paraffin waxes are white, translucent, tasteless and odourless solids consisting of a mixture of solid hydrocarbons of high molecular weight. They are soluble in benzene ligroin and warm alcohol. One of the properties of paraffin wax is that, it gives better surface finish.

\section{B. Carnauba wax}

This wax (known as "queen of waxes") is secreted by leaves of Brasilian palm tree (Copernicia pruniferacerifera), about $100 \mathrm{~g}$ per one tree in a year. It contains mainly fatty esters (80-85\%), free alcohols (10$15 \%)$, acids (3-6\%) and hydrocarbons (1-3\%). One of the properties of carnauba wax is that, it gives better dimensional accuracy.

\section{Microcrystalline wax}

Microcrystalline wax contains a higher percentage of is oparaffinic (branched) hydrocarbons and naphthenic hydrocarbons. It consists of high molecular weight saturated aliphatic hydrocarbons. The typical wax pattern is shown in figure 2 . The important properties of the waxes used in the present study are shown in Table 1

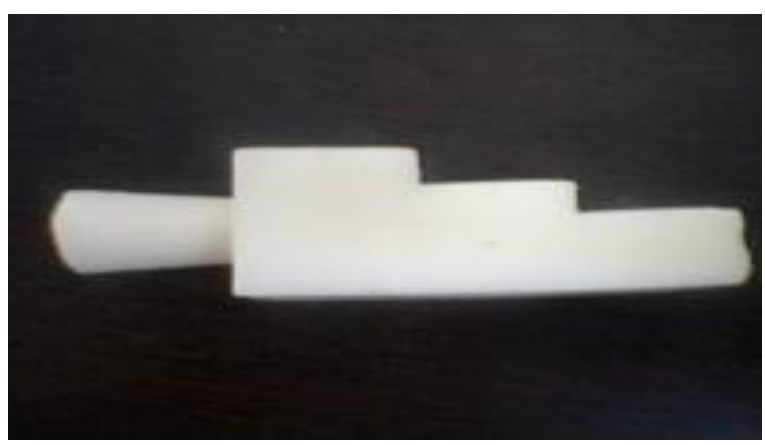

Fig 2 Typical wax pattern

Table 1: Properties of waxes used

\begin{tabular}{|l|l|c|c|c|}
\hline $\begin{array}{l}\text { Sr } \\
\text { No. }\end{array}$ & Name of wax & $\begin{array}{c}\text { Density } \\
(\mathrm{gm} / \mathrm{cc})\end{array}$ & $\begin{array}{c}\text { Melting point } \\
\left({ }^{0} \mathrm{C}\right)\end{array}$ & $\begin{array}{c}\text { Volumetric shrinkage } \\
(\%)\end{array}$ \\
\hline 1 & Paraffin wax & 0.78 & 64 & 6.20 \\
\hline 2 & Carnauba wax & 0.99 & 87 & 4.20 \\
\hline 3 & Microcrystalline wax & 0.83 & 82 & 3.82 \\
\hline
\end{tabular}

Three types of waxes namely paraffin wax, carnauba wax, microcrystalline waxes, with different melting temperatures between $64^{\circ} \mathrm{C}$ to $87^{\circ} \mathrm{C}$, are selected for the present study. Each wax is in solid state at room temperature. The proportions selected in the formation of different wax blends are given in Table 2. The weight of each wax is measured with an electronic balance.

Table 2: Wax blends and their proportions (by \% weight)

\begin{tabular}{|c|c|c|c|}
\hline Blend No. & Paraffin wax & Carnauba wax & Microcrystalline wax \\
\hline 1 & 40 & 40 & 20 \\
\hline 2 & 40 & 20 & 40 \\
\hline 3 & 50 & 50 & 0 \\
\hline 4 & 60 & 20 & 20 \\
\hline 5 & 70 & 10 & 20 \\
\hline
\end{tabular}


After conducting the experiment it is found that blend 4 could offer good properties. The ingredients of each wax blend are mixed and melted at $120{ }^{\circ} \mathrm{C}$ in a metal container with constant agitation in order to get homogeneous melt.

\section{EXPERIMENTAL INVESTIGATIONS}

The ingredient of blend 4 are mixed together to produce different wax blends (as shown in Table 2). The molten wax is then injected into the die. The die is heated up to $48{ }^{\circ} \mathrm{C}$ before injecting the wax and the wax injection temperature was raised up to $80{ }^{\circ} \mathrm{C}$. After injecting the wax into the die, it is cooled down to the room temperature. Then the pattern is removed from the die. The parameters controlled include wax temperature, injection temperature and injection pressure, die temperature, holding time. The selected range of the process parameters is shown in Table 3 .

Table 3: Ranges of process parameters

\begin{tabular}{|l|l|}
\hline Process parameter & Range \\
\hline Injection temperature & $65-80^{0} \mathrm{C}$ \\
\hline Die temperature & $44-48^{0} \mathrm{C}$ \\
\hline Injection force & $440-540 \mathrm{~N}$ \\
\hline Holding time & $8-10 \mathrm{~min}$ \\
\hline
\end{tabular}

We have used microwave oven for dewaxing of wax pattern. The wax model is placed inside a domestic type of microwave oven which is operating under a frequency of $2.45 \mathrm{GHZ}$, a power of $1100 \mathrm{~W}$, for a period of 15 min at room temperature and pressure of $1 \mathrm{~atm}$, reaching a maximum temperature of $110^{\circ} \mathrm{C}$. The main advantage of dewaxing by using microwave is that no purification treatment is required on the resulting wax. Dewaxing by using microwave was repeated up to 10 cycles.

\section{MEASUREMENT OF THE PROPERTIES}

After the pattern production the following properties are measured.
A) Volumetric shrinkage
B) Linear shrinkage
C) Surface roughness
D) Hardness
The properties are measured as follows.

\section{A) Volumetric shrinkage:}

The volumetric shrinkage is calculated as follows:

i) Apply a coating of grease on two halves of die to make it leak-proof from water and align the two halves of die together.

ii) Fill the die cavity with water and measure its volume with the help of a measuring flask. $\left(v_{d}\right)$

iii) Fill water in a measuring flask and note the initial reading $\left(v_{i}\right)$.

iv) Place the wax patterns made inside the measuring flask, volume rises and take the final reading. $\left(v_{f}\right)$

v) The difference between the two readings $\left(v_{f}-v_{i}\right)$ gives the volume of pattern.

vi) The percentage of volumetric contraction of the pattern is given by the following expression.

vii)

$$
\frac{\left\{V_{D}-\left(V_{f}-V_{i}\right)\right\}}{V_{D}} \times 100
$$

Volumetric coefficient of thermal expansion is calculated by the relationship as shown.

$$
\Delta v=\beta v_{i}\left(T i-T_{f}\right)
$$

Where, $\Delta \mathrm{V}=$ change in volume

$\beta=$ volumetric coefficient of thermal expansion

$$
\begin{aligned}
& v_{i}=\text { initial volume } \\
& T_{i}=\text { initial temperature } \\
& T_{f}=\text { final temperature }
\end{aligned}
$$




\section{B) Linear shrinkage}

Linear shrinkage can be calculated by measuring the difference between die dimensions and pattern dimensions produced.

\section{C) Surface Roughness}

Surface roughness of the each pattern is measured by using Optical Profiling System device which is of the type Veeco WYKO NTI 100.

\section{D) Hardness}

Hardness of each pattern is measured by using Penetrometer.

\section{RESULTS AND DISCUSSION}

Fig 3 shows changes in the percentage increase of volumetric shrinkage of wax blend with the number of repeated cycle using microwave dewaxing technique. As shown in fig. the volumetric shrinkage is increasing after each cycle. In cycle 10 the volumetric shrinkage is highest.

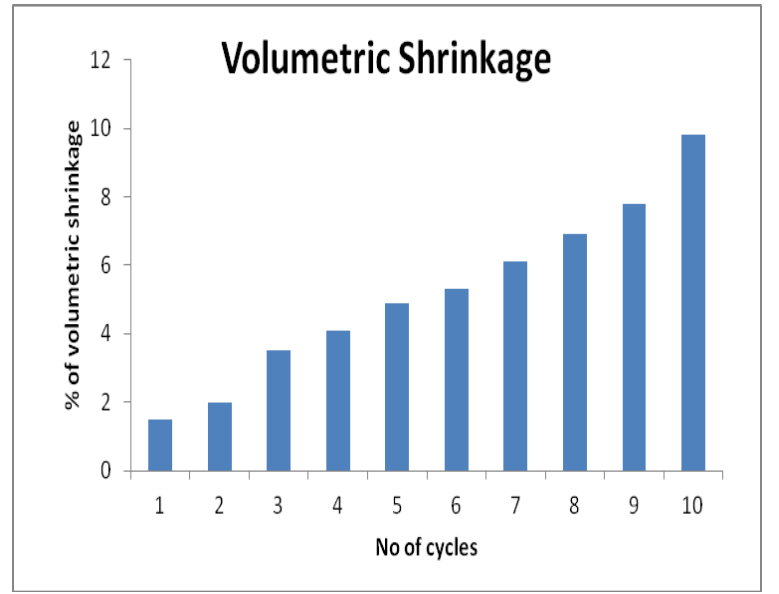

Fig 3 Volumetric shrinkage of wax blends

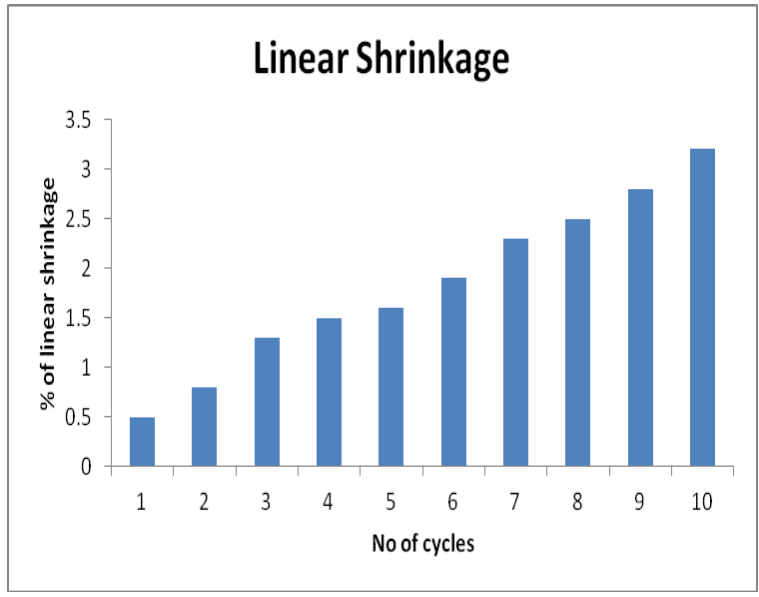

Fig 4 Linear shrinkage of wax blends

Fig 4 shows the change in linear shrinkage within number of simulated cycle for dewaxing in microwave oven. The percentage of linear shrinkage is increasing gradually in each repeated cycle. The gradual change in linear shrinkage is less as compared to gradual change in volumetric shrinkage. Fig 5 and Fig 6 show the variations in surface roughness and hardness of wax blend respectively after each repeated cycle.

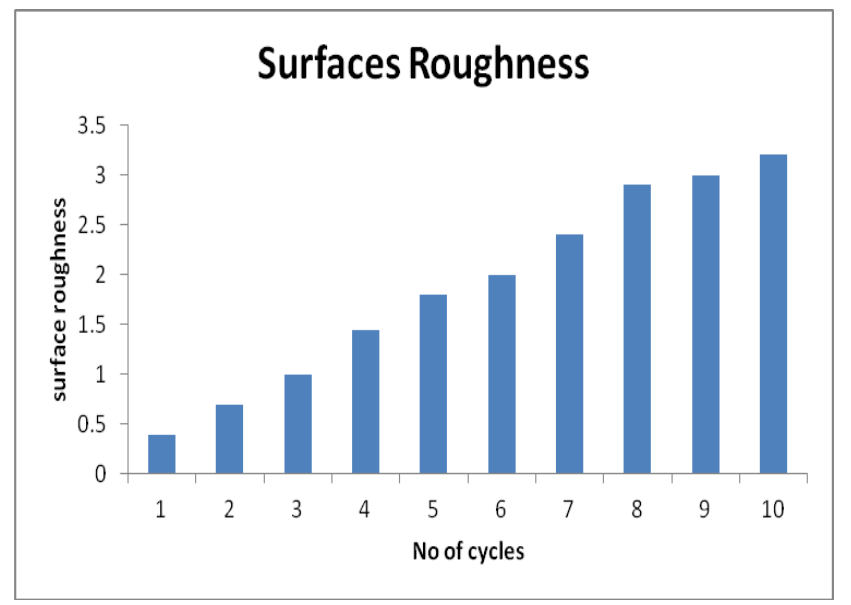

Fig 5 Surface roughness of wax blends 


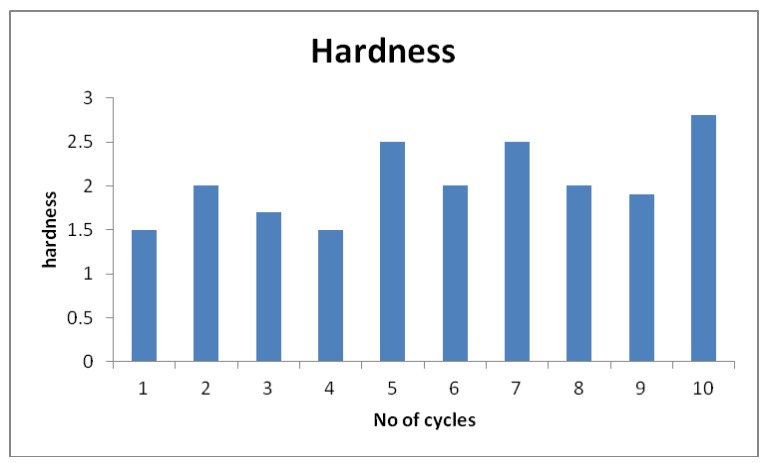

Fig 6 Hardness of wax blends

The hardness of wax is less altered during microwave dewaxing process. The change in hardness is not following any pattern rather it is some time decreasing and some time increasing. Microwave dewaxing is a milder treatment to the wax than any other method.

\section{CONCLUSIONS}

The following conclusions are drawn out of the experiments conducted on the wax blend selection and dewaxing of wax blend by using microwave oven.

1. The wax blend 4 with proportion of paraffin wax $60 \%$, carnauba wax $20 \%$ and microcrystalline $20 \%$ wax gives minimum volumetric shrinkage, linear shrinkage, surface roughness and better hardness.

2. The wax which was dewaxed in microwave oven shows, in general, less significant physical-chemical changes. There are very less changes in properties of wax after each repeated cycle.

3. The main advantage of microwave dewaxing is that wax does not require any purification of the recycling wax. The structural and chemical integrity of the pattern wax are consistent even after repetitive reuse.

\section{REFERENCES}

[1]. S. Tascyoglu, B. Inem, and N. Akar, "Conversion of an investment casting sprue wax to a pattern wax by the modification of its properties", Materials and Design, vol. 25, 2004, pp 499 - 505.

[2]. A.S. Sabau and S. Viswanathan, "Material properties for predicting wax pattern dimensions in investment casting", Material Science and Engineering A, vol. 362, 2003, pp 125-134.

[3]. V.F. Okhuysen, K. Padmanabhan, and R.C. Voigt, "Tooling allowance practices in investment casting industry", Proceedings of the 46th Annual Technical Meeting of the Investment Casting Institute, Orlando, USA, 1998, Paper no. 1.

[4]. J.C. Gebelin and M.R. Jolly, "Modeling of the investment casting process", Journal of Material Processing Technology, vol. 135, 2003, pp $291-300$.

[5]. W. Bonilla, S. H. Masood and P. Iovenitti, "An investigation of wax patterns for accuracy improvement in investment casting parts”, Bulletin of Industrial Research Institute of Swineburne, Melbourne, Australia, vol. 18,2001 , pp $348-356$.

[6]. B. Singh, P. Kumar, and B.K. Mishra, "Optimization of injection parameters for making wax patterns to be used in ceramic shell investment casting", Proceedings of Asian Symposium on Materials and Processing, 2006, Thailand.

[7]. Q. Liu, G. Sui and M.C. Leu, "Experimental Study on the ice pattern fabrication for the investment casting by rapid freeze prototyping (RFP)", Computers in Industry, vol. 48, 2002, pp 181 - 197.

[8]. Q. Liu, V.L. Richards, M.C. Leu, and S.M. Schmitt, "Dimensional accuracy and surface roughness of rapid freeze prototyping ice patterns and investment casting metal parts", International Journal of Advanced Manufacturing Technology, vol. 24, 2004, pp 485-495.

[9]. S.A.M. Rezavand and A.H. Behravesh, "An experimental investigation on dimensional stability of injected wax patterns of gas turbine blades", Journal of Materials Processing Technology, vol. 182, 2007, pp 580587.

[10]. M. Horacek and S. Lubos, "Influence of injection parameters to the dimensional stability of wax patterns", Proceedings of the Ninth World Conference on Investment Casting, San Francisco, California, USA, 1996, pp. 1-20.

[11]. P.K.D.V. Yarlagadda and T.S. Hock, "Statistical analysis on accuracy of wax patterns used in investment casting process", Journal of Materials Processing Technology, vol. 138, 2003, pp 75-81.

[12]. S. Tascroglu and N. Akar, "A novel alternative to the additives in investment casting pattern wax compositions", Materials and Design, vol. 24, 2003, pp 693 - 698. 